\title{
DOM, AMOR E DINHEIRO NO FUTEBOL DE ESPETÁCULO
}

\section{Arlei Sander Damo}

A redescoberta de Marcel Mauss, com a contribuição direta ou indireta do M.A.U.S.S., faz justiça com um dos mais importantes pensadores da primeira metade do século XX, cuja obra por muito tempo permaneceu diluída no espectro da Escola Sociológica Francesa, ou tida como superada pelo estruturalismo de Lévi-Strauss. As releituras atentas de Mauss, dentre as quais destacam-se os trabalhos de Bruno Karsenti (1997) e Camille Tarot (1999), ainda inéditos no Brasil, e as diversas publicações do M.A.U.U.S., animadas por Alain Caillé (1994; 1999; 2000; 2006), têm feito mais do que resgatá-lo do esquecimento, mostrando a densidade e a fecundidade deste pensador.

$\mathrm{O}$ ateliê montado por Mauss no interior da usina durkheimiana, como sugeriu Fournier (1994), investiu de forma ousada em temas tidos à

Artigo recebido em fevereiro/2008

Aprovado em março/2008 época como periféricos - tal o caso da magia, do sacrifício, da prece, das técnicas corporais, entre outros. Não seria de estranhar, pois, se a contribuição maussiana se mostrasse interessante para se pensar o fenômeno esportivo, um tema relativamente novo para as ciências sociais. A tendência neste caso seria começar pelo texto sobre as técnicas corporais, afinal os esportes são formas de dispor do corpo e do movimento visando, entre outras coisas, à produção de espetáculos. No entanto, outros trabalhos de Mauss também podem servir de inspiração, como é o caso do Ensaio sobre a dádiva, sua obra prima. Mas afinal, qual seria a relação possível entre as técnicas corporais e a dádiva?

Este texto não é um ensaio teórico que pretende articular os conceitos maussianos, antes um esforço para compreender a dinâmica entre o amor dos torcedores pelos clubes ditos do coração e o dinheiro que eles destinam aos atletas que 
os representam nas disputas propriamente futebolísticas. Para entender essa dinâmica é preciso ter em conta o fato de que os futebolistas são profissionais reconhecidos como portadores de dom, que eles dispõem aos torcedores em troca de remuneração. Estes, por seu turno, são engajados ao futebol de espetáculo pelo pertencimento clubístico, uma modalidade de vínculo que os amalgama aos "clubes do coração". Trata-se, pois, de uma espécie de dádiva sagrada que não pode ser trocada, já que é herdada pelo indivíduo da rede de sociabilidade primária como uma espécie de pacto de sangue.

Proponho-me desvendar a dinâmica entre profissionais e amadores (atletas e torcedores), a natureza inversa de seus dons e as tensões entre o valor utilitário e o valor simbólico do dinheiro. Parto de um dilema surgido durante a realização de uma etnografia nos centros de formação de jogadores acerca dos diferentes usos da noção de dom, a saber, o dom que é sinônimo de talento e o dom, sinônimo de dádiva. No primeiro caso dialogo, explícita ou implicitamente, com a bibliografia desdobrada da preocupação maussiana sobre as técnicas corporais; mas será com a acepção do dom como sinônimo de dádiva que me ocuparei mais detidamente. Ocorre que esta percepção, do dom como dádiva, tende a exercer uma força sobre o dinheiro, derivado do dom como talento, forçando os jogadores à retribuição. Pretendo explicitar a natureza desta força que faz o dinheiro do dom circular, beneficiando a rede de relações dos atletas, aqui definida como entourage.

Num cenário em que o dinheiro tem cada vez mais importância na mediação do contrato entre clubes e jogadores, enquanto os afetos continuam sendo a base do contrato entre clubes e torcedores, a circulação dos profissionais e seu duplo estatuto, de pessoa e mercadoria, é seguidamente tensionada. Concluirei este texto apresentando um caso ilustrativo de ruptura do contrato afetivo entre a torcida e um jogador, depois que este encerrou seu contrato legal com o clube e decidiu negociar no mercado sua força de trabalho, como é legítimo para qualquer trabalhador moderno. Amor e dinheiro mostram-se, neste caso, uma mistura explosiva.

\section{A alquimia do dom no contexto da formação de "pés-de-obra"}

No contexto do futebol de espetáculo, o termo dom é usado com muita freqüência, em diferentes acepções, sendo uma delas sinônimo de talento. Ter dom não é a única condição para estar num centro de formação, pois o dom precisa ser lapidado, como afirmam os profissionais que trabalham nesses centros. Os atletas em formação normalmente têm uma percepção difusa sobre o assunto, mas nenhum deles jamais admitiria não ter "bola no corpo", outro termo equivalente para o dom. Ao longo da etnografia iniciada no Sport Club Internacional, de Porto Alegre, e continuada no Olympique Marseille e em outros centros de formação franceses (Damo, 2005, 2007), fui percebendo que os formadores preferiam os termos "talento" e "potencial" em vez de dom. Descobri que parte da resistência advinha da crença segundo a qual a categoria dom encobriria o trabalho mundano, a cargo dos formadores, de inculcação dos capitais corporais exigidos pelo profissionalismo - um processo que necessita em torno de 5.000 horas e se arrasta por várias etapas ao longo de oito a dez anos.

De outra parte, notei que o encobrimento da aprendizagem era algo freqüente nas narrativas de atletas consagrados, e também de artistas em geral, cujo sucesso tende a ser explicado como natural ou dadivoso. Passei a ler biografias de ex-jogadores, prestar atenção em depoimentos, e na maioria dos casos podia-se notar um misto de romantização e naturalização do aprendizado. As narrativas mito-poéticas acerca das origens das disposições futebolísticas tinham muita proximidade com aquelas relativas ao despertar vocacional dos clérigos, na medida em que o sujeito se constrói como um predestinado (Suaud, 1978). Essas representações do dom davam conta de que o termo poderia ser tomado também como sinônimo de dádiva, recebido e/ou herdado da natureza ou de divindades.

Conquanto os nativos possam fazer uso das duas acepções ao mesmo tempo, parecia-me claro que elas tinham implicações distintas. Havia pelo menos duas possibilidades de resolver o impasse. Uma delas implicando o retorno à bibliografia convencional sobre o dom, embora na época ti- 
vesse certa resistência em fazê-lo, provavelmente pela influência do trabalho de campo, muito voltado para as tecnologias do treinamento, que me faziam ver o mundo pelos olhos dos atletas e dos formadores. A outra possibilidade seria não problematizar esta questão, contando para isso com o suporte da etnografia de Wacquant (2002) junto aos boxeadores de Chicago. Acabei optando pelo retorno à bibliografia sobre o dom, como mostrarei adiante, mas devo explicitar as razões pelas quais evitei a simples apropriação da solução apresentada por Wacquant.

Tanto quanto os futebolistas brasileiros, os boxeadores de Wacquant referiam-se seguidamente ao dom. Wacquant, que na maior parte do livro usa as teorias nativas quando deseja explicar o processo de aprendizado do boxe, tomou outro rumo em relação ao dom. Na tentativa de desnaturalizar o "mito indígena", ele aplicou o "mito bourdiano", diluindo o dom no conceito de habitus. Ao fim e ao cabo, Wacquant usou habitus para explicar a crença nativa no dom, como se pretendesse salvá-lo do que ele constatou ser um equívoco de suas percepções acerca de si mesmos: "A expressão 'boxeador natural' (a natural), que muitas vezes retorna ao vernáculo das academias, designa essa natureza cultivada, cuja gênese social tornouse invisível para aqueles que a percebem por meio das categorias mentais que são o produto dela" (2002, p. 120).

Há ao menos dois problemas nesta interpretação. O primeiro é abusar da noção de habitus, um coringa que dá a impressão de resolver toda a sorte de impasse teórico, mas que, por vezes, simplesmente mascara a solução. ${ }^{1}$ O segundo problema, ainda mais grave, é um desdém pela questão da linguagem e, por extensão, pela dimensão simbólica. Há certos termos, e o dom é um deles, cujo uso social é cercado de enigmas, em relação aos quais nos compete aprofundar as investigações e não desvencilhar-se delas por intermédio de subterfúgios. O fato de os boxeadores profissionais e mesmo dos meus informantes crerem no dom - em algo intangível à intervenção, como uma espécie de natureza da qual se dispõe, mas não pode ser totalmente manipulada - não contradiz uma outra crença, segundo a qual, mediante treinamento metódico, é que se faz de um predestinado um campeão. Assim como as crianças podem acreditar, simultaneamente, que Papai Noel existe, e que são seus pais quem compram os presentes de Natal, tal a metáfora de Paul Veyne (1984) para falar da coexistência (e mesmo da eficácia) de crenças antitéticas, atletas tendem a crer que são ao mesmo tempo predestinados e precisam empenhar-se de corpo e alma para que o sucesso pessoal seja alcançado. Eles crêem no dom, como um mistério que faz com que alguns sejam predestinados, e também no treinamento, cujo esforço mundano é contrário à idéia de mistério, de sorte, de destino e assim por diante.

Diante da dupla exigência que se impunha, de preservar as teorias nativas acerca das virtudes futebolísticas e, ao mesmo tempo, encontrar uma explicação de natureza teórica sobre tais questões, retornei ao Ensaio sobre a dádiva, à crítica que lhe foi dirigida por Lévi-Strauss (2003) na introdução, e aos críticos de ambos. O primeiro passo foi isolar, por assim dizer, a palavra e a coisa, ou seja, proceder tal qual a sugestão de Lévi-Strauss, tratando o dom como um "significante flutuante", um termo que não possui um significado preciso, pelo contrário, é empregado em diversas circunstâncias como condição de possibilidade de expressão de certas antinomias que são próprias ao pensamento simbólico (quando avessas ao rigor da lógica formal) (Lévi-Strauss, 2003, p. 43). ${ }^{2} \mathrm{O}$ segundo passo, seguindo a sugestão de Tarot (1999) e Caillé (1999), para quem é prudente destinar a Mauss e a Lévi-Strauss seus devidos lugares, foi retornar a Mauss para pensar nos desdobramentos possíveis diante da presença de uma categoria prenhe de significações. Ou seja, retornar à etnografia para entender os mistérios do dom, não enquanto uma categoria positiva, mas como expressão do pensamento, e os desdobramentos concretos dessa representação, especialmente no caso em que o dom é sinônimo de dádiva.

\section{A manipulação do dom pelo entourage}

Com o objetivo de preservar o sentido nativo atribuído ao dom, forjei alguns conceitos alternativos, como é o caso de capital futebolístico, uma modalidade de capital corporal que compreende um leque extenso de aptidões (inatas $\mathrm{e}$ 
desenvolvidas por meio dos treinamentos), definidas segundo as exigências de um dado estágio de desenvolvimento das performances visando ao espetáculo. ${ }^{3}$ A questão da origem desses capitais - uma verdadeira fascinação entre os formadores - não é especialidade da antropologia. Em contrapartida, há muito para se saber acerca das implicações decorrentes do fato de alguém ser reconhecido como um predestinado, no sentido positivo do termo - de privilegiado, agraciado, presenteado e assim por diante. Ocorre que certos atletas são especialmente dotados de capitais futebolísticos, e o futebol de espetáculo é generoso com os privilegiados. ${ }^{4}$

Os casos de futebolistas que gastaram toda a fortuna que receberam são freqüentes, mas ao contrário de reiterar que eles não têm estrutura para gerir suas carreiras, não sabem o valor do dinheiro e coisas do gênero, proponho uma interpretação alternativa. Muitos boleiros têm, isto sim, dificuldade de reter seus ganhos em razão de duas forças convergentes que atuam sobre eles: certo modelo idealizado de bondade dos ricos, muito freqüente entre os grupos populares - segundo o qual o bom rico é o que distribui a riqueza, e não o que acumula indefinidamente, como sugere a ética capitalista puritana (Veyne, 1976); e um conjunto de representações acerca do dom, urdidas no próprio meio futebolístico, segundo as quais o dinheiro que é produto do dom (como sinônimo de talento e dádiva, neste caso) é propenso à redistribuição, afinal o dom não pertence ao sujeito, antes se manifesta nele. 5

Como resta pouco espaço para argüir sobre os modelos de riqueza e de pobreza dos grupos populares, de onde é recrutada a maioria dos futebolistas no Brasil, concentrarei os argumentos na seguinte questão: a influência da crença no dom sobre o destino do dinheiro que é tido como derivado do dom.

A hipótese desenvolvida a partir do acompanhamento etnográfico de atletas em formação é de que aquele que se reconhece como predestinado se torna suscetível a retribuir, de algum modo, à dádiva que acredita estar na origem de todos os investimentos. Isso não é obra de um indivíduo isolado que, depois de um exame de consciência, sente-se impelido à retribuição. Há, isto sim, um sistema simbólico em ação, em algumas configu- rações com mais ênfase do que em outras, de tal modo que a adesão e a extensão da cadeia de reciprocidades dependem de quão susceptível a ela for o sujeito em quem o dom é reconhecido. Dar uma casa para a família, e sobretudo para a mãe, se ela não tiver marido, é algo sagrado para os meninos de grupos populares. Do dirigente ao técni$\mathrm{co}$, passando pelos colegas e os familiares, todos os pressionam nesse sentido.

A crença no dom é muito freqüente no entorno dos jogadores egressos de grupos populares, em que a ideologia individualista é mais difusa. Mas o simples fato de alguém ser reconhecido ou declarar-se portador de dom não implica, contudo, na constituição de uma cadeia mecânica de reciprocidades. Para tanto, será necessária a existência de uma configuração social de pequena escala, definida como entourage, a lembrar e até mesmo a exigir que os produtos do dom sejam partilhados - pode ser em espécie, presentes, imóveis, empregos, entre outros. A circulação do dom vai depender, portanto, de quão susceptíveis a fazêlo circular estejam o seu portador e aqueles no seu entorno. Dizendo de outro modo, o dom não entra em circulação por haver nele uma força misteriosa - um hau ou algo que o valha - e muito menos pelo fato de essa força atuar, isoladamente, sobre a consciência daquele em quem o dom é reconhecido. ${ }^{6}$

Para ter direito à redistribuição dos ganhos tidos como produtos do dom é preciso fazer por merecer, conquanto existam mil e uma estratégias para tal, dentre as quais a contração de um crédito por intermédio de favores. O que parece ser um privilégio para esses meninos, que se valem de presentes, favores e bajulações para avaliar seus status, é também uma abertura para os agentes/empresários. As carências econômicas de origem e o desgaste emocional que a disciplina e a competição dos centros de formação exigem tornam esses adolescentes vulneráveis aos agentes. Relógios, tênis, chuteiras, roupas de grife e outros fetiches de adolescentes misturam-se a dinheiro em espécie, emprego a familiares, falsificação de documentos e uma série interminável de itens disponibilizados estrategicamente pelos empresários. Eles sabem que é dando que se recebe, e com dádivas eles adquirem a confiança e, não raro, o direito de serem seus procuradores. Uma vez constituídos le- 
galmente como tal, eles podem negociar salários, direitos federativos e, em alguns casos, administrar os ganhos dos atletas, os problemas familiares e assim por diante. Como a procuração só tem validade legal depois de o jovem ter completado 16 anos, não é raro que este contrato, de natureza legal, seja precedido por outro, de natureza moral, estabelecido há mais tempo e por intermédio de dádivas, pelo qual a família do atleta em formação se sente comprometida com o agente/empresário. Acompanhando um desses agentes durante o trabalho de campo, fui apresentado ao pai de um garoto de 14 anos que estava "empregado" na empresa do meu informante. A empresa foi apresentada como uma "agência de atletas", "para auxiliar os boleiros, como fazem as agências de modelos, de artistas famosos", embora o que mais chamasse a atenção fossem os equipamentos usados na edição de vídeos de jovens talentos que seriam negociados. O pai do garoto, que jogava no Infantil do Inter, estava sentado numa escrivaninha em sala anexa à ilha de edição, e ocupava-se em fumar e ler jornais: isto era o seu "emprego", literalmente.

Em que pese a quantidade de oportunistas, via de regra o entourage é integrada pela parentela e suas redes, o que implica que ela aflora com o dom, mas que já está constituída desde longa data. A constatação de um profissional que trabalha há anos nas categorias de base do Inter é lapidar: "quando o cara é um pobre diabo, sem perspectiva, não tem ninguém por ele; não tem pai, nem mãe, nem parente, nada. Aí recebe uma chance, faz um gol, aparece na TV e pronto: tem tios, sobrinhos, vizinhos, tudo!". O entourage tende a se mobilizar para dar suporte a esses jovens, e pode ser expandida conforme as conveniências e as possibilidades. Seu Jorge, por exemplo, passou a residir com o filho em Marseille, quando este trocou o Flamengo pelo clube francês. Nada que se compare, no entanto, ao pai de outro informante, que além dos jogos assistia aos treinamentos no Beira-Rio, condição galgada a partir de um emprego, e depois de outro, ambos de motorista de agente/empresário de jogador de futebol.

Nem todos os pais que eu conheci aceitariam entregar a tutela do filho em troca de emprego; nem todas as famílias trocariam um contrato de trabalho - que garante ao clube o vínculo federativo e, portanto, o passe - por uma moradia.
Outros, no entanto, não têm qualquer restrição moral a esse tipo de conduta, embora as condições econômicas do entourage sejam um elemento importante a ser considerado. A capacidade de os agentes/empresários manipularem os códigos desses grupos, sobretudo no âmbito das classes populares, dos quais eles próprios são freqüentemente egressos, é o que garante o estabelecimento de vínculos bem-sucedidos com os meninos e seus familiares, quase sempre com o pai, e não porque as famílias sejam incapazes de gerir seus próprios projetos, ainda que por vezes enfrentem obstáculos das mais diversas ordens de carência.

O dom tido como sinônimo de dádiva institui, pois, uma cadeia de reciprocidades múltiplas, existindo mesmo onde não é manifesto abertamente. A força do dom reside na crença dos grupos que o reconhecem e o manipulam. Isto é, são as configurações sociais que geram o dom as responsáveis por orientar a sua manipulação. Os dividendos provenientes do dom não são propriamente redistribuídos, mas disponibilizados no circuito do entourage. A partir daí são desencadeadas uma série de negociações, não raro conflituosas, em torno dos direitos e deveres de acesso às benesses geradas pelo dom. Muitas vezes as disputas entre o entourage são tão acirradas que os próprios atletas acabam envolvidos, apresentando queda de rendimento nos treinamentos e nos jogos.

\section{Engajamento afetivo e trocas jocosas}

Sem público não haveria espetáculo, tampouco reconhecimento e remuneração para o dom futebolístico. Sem o suporte do clubismo, o futebol não teria forjado um público fiel, e jamais teria alcançado tamanha popularidade. Nos tempos do amadorismo, em que ocorreu a diáspora esportiva, os clubes foram importantes centros de difusão do ideário romântico. Desde então ocorreram diversas transformações em relação à prática e aos valores do esporte, e a importância dos clubes só aumentou. No caso específico do futebol, um clube é uma instituição político-adminitrativa responsável pela organização de uma equipe que compete com outras e, portanto, compete com outros clubes. Além dessa atribuição, os clubes precisam integrar os membros da comunidade afetiva que 
gravitam no seu entorno e preservar a memória da instituição - criar símbolos de identificação, relembrar conquistas importantes etc. De outra parte, eles são como totens, entidades de natureza simbólica que condensam a representação de uma dada comunidade de sentimento, cujo sentido é em grande parte constituído pela existência de outras comunidades do mesmo gênero. ${ }^{?}$

O engajamento nessas comunidades é essencial para se experimentar a pleno as emoções futebolísticas (Bromberger, 1995). A escolha de um clube não é propriamente racional, mas pressupõe sedução e cooptação, um proselitismo exercido sobre os neófitos pelos torcedores já engajados. Inculcar o pertencimento clubístico é competência da rede de sociabilidade primária, normalmente de um familiar ou amigo muito próximo, o que acarreta a indexação do clubismo a outro sistema de pertença, no qual o fluxo de emoções e solidariedades é intenso. ${ }^{8}$ Dadas as influências da parentela consangüínea na escolha do clube, torna-se mais compreensível a razão pela qual o vínculo é considerado eterno - como diz o hino do Flamengo, "uma vez Flamengo... Flamengo até morrer". A idéia de que os pactos de sangue não podem ser rompidos, valor amplamente disseminado em nossa cultura (Schneider, 1992, p. 195), certamente tem muita influência no padrão de comportamento dos torcedores, o que fica explícito quando se declaram fiéis aos clubes mesmo em uma situação de rebaixamento.

Como todos acabam sendo seduzidos ou constrangidos pela parentela agnática a torcer por um determinado clube, poder-se-ia pensar no pertencimento como uma modalidade de dom sagrado, que não pode ser trocado, reforçando no plano afetivo as solidariedades parentais, a idéia de que a família perde e ganha unida através do futebol. Herdar a pertença significa habituar-se aos altos e baixos do desempenho dos times - à alegria pela vitória no jogo de domingo segue a tristeza pela derrota do time na quarta-feira, ano após ano, indefinidamente. O que chama a atenção no clubismo é que, tal qual no totemismo, as identidades são diacríticas e os sentimentos antitéticos. A desolação dos torcedores de um clube é o combustível para a euforia da torcida adversária. Aprender a amar o Inter, o Corinthians e o Cruzeiro, por exemplo, é tão importante quanto detestar, respectivamente, o Grêmio, o Palmeiras e o Atlético.

O clubismo institui um sistema de dádivas no qual não circulam propriamente presentes, mas zombarias. Nas trocas entre os torcedores rivais prevalecem os insultos, as provocações e, portanto, a incitação ao conflito. Mas os insultos ordinários não são da mesma ordem daqueles que ocorrem em circunstâncias rituais - como nos estádios e em outros espaços em dias de jogos -, são relativamente amenos e assemelham-se, sob vários aspectos, ao tom ambíguo entre a hostilidade e a amistosidade, ao que Mauss denominou joking relationships (1969 [1926], pp. 109-125).9 Cada sociedade tem seu próprio parentesco por brincadeira, sugere Mauss, recomendando atenção para o fluxo das trocas e as regras atinentes. O esclarecimento desses aspectos explicitaria "a natureza e a função de elementos estéticos importantes, misturados [...] aos elementos da vida social" (Idem, p. 124).

As gozações incluem um leque extenso de termos como "tirar sarro", "arriar-se", "deitar-se", "pegar-no-pé", entre outros, muitos deles com conotação erótica. No estádio, escutam-se xingamentos ostensivos, mas, fora dele, o que se faz é zombar de alguém com quem se tem intimidade, alguém que pertença à sua rede de sociabilidade - amigos, colegas de trabalhos, parentes etc. Como se trata de algo lícito e aceito por todos, um subordinado pode, por exemplo, se dar o luxo de zombar do superior, o aluno, do professor, e sucessivamente, de tal modo que pode haver uma inversão das hierarquias de status, como é característico no humor popular (Bakthin, 1993). A licenciosidade instaurada faz do pertencimento clubístico um poderoso dispositivo de comunicação transversal, rompendo as fronteiras habituais de status - pobre/rico, negro/branco, criança/adulto, entre outras. Não estou, em hipótese alguma, fazendo apologia do clubismo, afinal até mesmo o mais humilde cidadão sabe que o futebol não muda a vida de ninguém. O que ele faz é sacudir temporariamente as hierarquias convencionais, como já afirmou Geertz (1989) em relação à briga de galos balinesa, e nisto consiste boa parte da sua eficácia simbólica.

Pode-se não gostar de futebol, até mesmo detestá-lo. Nesse caso o sujeito não pertence a esse universo, não correndo o risco de ser insultado. 
Mas o que o sistema não tolera, de modo algum, é a ambivalência: ora gostar de futebol, ora não; ora torcer por um clube, ora por outro. Essa atitude não permite a brincadeira, a circulação - dar e receber - das insinuações jocosas, não se conformando aos princípios elementares das identidades e das alteridades sugeridas pelo sistema.

\section{Amor, dinheiro e traição}

Com a espetacularização do futebol os torcedores tornaram-se a única categoria de agentes amadores, na dupla conotação do termo. Por um lado, são os que amam efetivamente o clube, em certos casos entregando-se a ele por completo; por outro, no sentido depreciativo, são os que não dispõem de capitais futebolísticos para estar em campo, sendo obrigados a depositar suas fichas nos profissionais que os representam. Resta-lhes a co-participação, razão pela qual se diz que os torcedores não vão ao estádio para assistir a um jogo, mas para dar suporte a uma das partes envolvidas na disputa.

À diferença dos tempos do futebol amador, em que os atletas eram escolhidos entre os sócios do clube, a profissionalização exigiu e possibilitou uma ampla base de recrutamento. Os vínculos dos atletas com os clubes passaram a ser mediados pelas leis trabalhistas, tendo os atletas a liberdade de oferecer sua força de trabalho conforme a conveniência e as possibilidades. Os torcedores, ao contrário, não têm a prerrogativa da circulação, pois o pertencimento clubístico está alicerçado em um contrato perpétuo, na contramão da modernidade.

O privilégio que esse sistema concede aos jogadores gera desconfiança entre os torcedores. Afinal, eles recebem seus salários mesmo quando o time perde, deixando aqueles expostos às jocosidades de seus rivais. Os torcedores toleram determinados fracassos, desde que não sejam freqüentes a ponto de comprometer a reputação do clube. Em casos especiais, quando percebem a disposição dos atletas para a luta, podem se solidarizar com eles mesmo na derrota. De qualquer modo, o romantismo que permeia o sistema vê nos interesses individuais e utilitários uma fonte de corrupção permanente, como se amor e dinheiro fossem irreconciliáveis por natureza (Simmel, 1998).
Uma das estratégias dos dirigentes para manter o torcedor identificado com o time são os investimentos feitos nas categorias de base. As pessoas acreditam que os atletas formados na base incorporam o ideário do clube. Mesmo um clube milionário como o Real Madrid, que recrutou uma legião de jogadores conhecidos como "galácticos" por volta de 2003, não se descuidou de seu "terreno", pois é dali que saem os verdadeiros merengues, como crêem os madrilenhos (Damo, 2007, pp. 127-136). O poder da crença de que amor e dinheiro são irreconciliáveis fica claro no exemplo de um caso limite, em que um jogador, antes aclamado, passa a ser odiado pela torcida que se sentiu traída por ele.

Em dezembro de 1987 os jornais de Porto Alegre noticiaram o "rapto" de Roberto de Assis Moreira, um jovem de 16 anos que integrava as categorias de base do Grêmio, onde era conhecido apenas como Assis e comparado a Maradona, então no auge de sua carreira. Os dirigentes do clube deram pela sua ausência nos treinamentos e descobriram que ele havia sido levado por um empresário à Itália para um período de testes no Torino. Os repórteres foram entrevistar o pai do garoto, Seu João, que dizia ter em casa o verdadeiro prodígio da família, à época com 6 anos. Para reaver Assis os dirigentes do Grêmio deram à família uma casa de dois pisos, com piscina e vista para o estuário do Guaíba, e obtiveram a garantia de que o caçula ingressaria nas escolinhas do clube, o que efetivamente ocorreu. A morte de Seu João, em 1989, cujo corpo foi encontrado na piscina da própria casa, delineou contornos trágicos à história da família Assis Moreira. Assis debutaria entre os profissionais pouco antes da morte do pai, mas seu desempenho irregular acabou criando a impressão de que ele era mais uma promessa irrealizada, sendo vendido em 1992 por um valor aquém do projetado.

Ronaldo de Assis Moreira, o caçula, evoluiu à sombra do irmão mais velho, tendo sido convocado para as seleções de base da CBF desde os 14 anos. O fato de Assis ter "ficado na promessa", como dizem os torcedores, fez com que Ronaldinho fosse tratado com certa desconfiança, sobretudo nos primeiros jogos entre profissionais, quando alternava altos e baixos desempenhos, por vezes ausentando-se das responsabilidades que os 
torcedores exigem de atletas talentosos. A futrica da mídia não cessava de lembrar o irmão, e os torcedores estavam ficando impacientes.

Ronaldinho completara 18 anos três meses antes daquela tarde de domingo cinzenta, em junho de 1999, em que os gremistas depositavam nele suas fichas para vencer o terceiro jogo contra o Internacional, decisivo para o título regional daquele ano. Ronaldinho já havia feito um dos gols da vitória no jogo anterior, mas naquela tarde ele realmente se superou: fez o gol do título ainda no primeiro tempo e passou o segundo fustigando Dunga, o sisudo ex-capitão da seleção, com dribles desconcertantes. "Olha lá, ele está carimbando a aposentadoria do Dunga!", bradavam os gremistas extasiados, afinal aquela luxúria só podia ser coisa de um predestinado, que além de tudo era gremista de coração. No dia seguinte, Ronaldinho foi convocado para a seleção brasileira, fez um gol antológico na estréia, e o mundo da bola abriu-lhe todas as portas.

Por ter passado quase metade da sua vida no interior do clube, os torcedores acreditavam que ele havia incorporado o pertencimento, tornandose um amador entre os profissionais. Além das performances excepcionais, Ronaldinho especializara-se em demonstrar efusivamente seu apreço pelo clube, fazendo declarações de amor eterno, beijando o dístico nas comemorações, provocando os colorados (como fizera com Dunga) e assim por diante. O encantamento recíproco parecia inabalável, a ponto de o presidente do Grêmio tornar pública a recusa por propostas milionárias de clubes europeus. O jogador dizia-se satisfeito em Porto Alegre, perto de sua família, despreocupado em relação ao futuro e realizado em meio aos afagos da torcida que ele tanto amava.

O vínculo legal de Ronaldinho com o Grêmio chegaria ao fim em 2001. Meses antes ele foi procurado pelos dirigentes que estavam certos de sua renovação, ao menos até a Copa do Mundo do ano seguinte, mas não chegaram a um acordo. Assessorado pelo irmão, já em final de carreira, Ronaldinho dava entrevistas evasivas sobre a negociação com o Grêmio, fazendo crer que eles resolveriam o impasse a bom termo no tempo devido. Nos bastidores, Assis tratava da transferência de Ronaldinho para a Europa, e quando o Grêmio bancou sua proposta salarial descobriu que o jo- gador havia assinado um pré-contrato com o clube Paris-Sait-Germain. Encerrado o contrato com o Grêmio, Ronaldinho estava livre para jogar onde quisesse, e o clube perdera o direito à compensação que a Fifa exige quando da transferência de atletas com contrato em vigor - o popular "passe". Além de não mais contar com o futebol de Ronaldinho, os gremistas viram sua mercadoria mais preciosa esvair-se. ${ }^{10}$

No seu último jogo pelo clube, Ronaldinho teve uma atuação apática. Foi substituído em meio ao segundo tempo - propositalmente, sugerem as más línguas - e um coquetel de vaias e xingamentos substituíram os aplausos de outras ocasiões. Moedas foram arremessadas em sua direção enquanto percorria cabisbaixo o caminho dos vestiários. "Se era por dinheiro que partia, como um reles mercenário, então que juntasse também às moedas!”. A frustração dos torcedores era clara, pois não poderiam seguir Ronaldinho já que estavam presos ao Grêmio por uma relação construída desde muito cedo e que, como já vimos, resulta numa fidelidade exacerbada. A imagem dos torcedores atirando moedas é muito forte e possui um imenso valor simbólico. Não tinha só o sentido de acusar o jogador de ser um mercenário, mas mostrava também o quão vil é o dinheiro para o ideário clubístico. A trajetória de Ronaldinho no Grêmio ilustra muito bem o vínculo conflituoso entre amor e dinheiro no bojo das relações entre atletas e torcedores. Mesmo sem um aprofundamento da análise dessa trajetória, pode-se afirmar que o processo de transferência do jogador foi mal conduzido do ponto de vista afetivo, tanto por Ronaldinho como pelo Grêmio.

Durante a etnografia realizada nos centros de formação, tive a oportunidade de acompanhar a venda de Nilmar, então jogador do Internacional, para um clube francês. $O$ atleta despediu-se do clube afirmando que o negócio era bom para ambas as partes, e os torcedores desejaram-lhe boa sorte. Os 9 milhões de euros que o Inter teria recebido como compensação amainou o sentimento de perda, e Nilmar seria recontratado pelo clube três anos depois, com a chancela dos torcedores que o tratam como ídolo. Um exemplo completamente oposto ao de Ronaldinho, portanto.

A compra e a venda de jogadores tornou-se rotina no futebol de espetáculo, e se existem torcedores desapontados com este estado de coisas, 
não menos verdade é que há outros conformados, desde que o clube e, por extensão, a torcida não seja ludibriada. Na realidade, a maneira como Ronaldinho conduziu o processo de sua saída do clube fez parecer que ele agia exclusivamente em interesse próprio, com o agravante de não ser um profissional qualquer; fora criado no quintal do Estádio Olímpico, a casa dos gremistas, o que fortifica sobremaneira o vínculo afetivo com a torcida.

Sem retornar a Mauss é difícil compreender - sem julgar (e sem condenar) - este tipo de transação em que se misturam pessoas e coisas. Como mostra também Zelizer (1992) em seu trabalho sobre o comércio de bebês nos Estados Unidos, estipular preço para seres humanos não parece ser um problema prático. Conquanto esse tipo de comércio seja mais extenso do que gostaríamos de acreditar, e na maioria dos casos solapa dos seres humanos comercializados a própria definição de pessoa (Solinas, 1994), é preciso admitir que a sociedade em geral faz vistas grossas a esse respeito. A naturalidade com que se estipula o preço de jogadores por vezes impressiona.

A diferença entre os casos de Ronaldinho e Nilmar mostra, no entanto, que existem certos códigos morais orientando esse mercado. Mas tratase de um consolo? Em ambos os casos as transações beneficiaram os jogadores, o que deixa a impressão de que o status de pessoa é preservado nessas situações. Já as moedas lançadas pelos torcedores gremistas indicam, em contrapartida, que a dignidade do atleta foi arranhada, uma vez que ele teria dado mais importância ao contrato monetário do que ao afetivo. Seriam, pois, os afetos, o último reduto da mercadorização?

\section{Considerações finais}

Não há como pensar o dom artístico e, particularmente, o dom futebolístico, sem o público, pois o dom não sugere substância, mas relação, troca, circulação. Na relação entre torcedores e atletas há uma série de regras de moral e de direito negociadas concretamente, e creio que elas não dizem respeito apenas ao âmbito esportivo. $\mathrm{O}$ fato do engajamento dos torcedores aos clubes ser amalgamado por sentimentos que se confundem com os laços de parentesco potencializa a drama- tização da solidariedade e da honra, sendo este último um valor masculino por excelência. O que torna esse universo interessante às ciências sociais é o fato de que a dinâmica dessas "comunidades afetivas" está, em grande parte, vinculada aos destinos de um jogo, disputado por especialistas treinados e pagos para tal.

O dom que provém do uso das técnicas corporais, responsável pela geração de divisas aos atletas, não beneficia diretamente apenas o indivíduo em quem ele se manifesta. Isto é possível graças, sobretudo, ao incremento da dimensão pecuniária da relação entre clubes e jogadores; mas não é apenas isto que está em jogo para os atletas: eles também são ávidos por reconhecimento e, em casos extremos, tornam-se dependentes do carinho da torcida, chegando a sonhar com isso, como me confessou um ex-boleiro. Certamente vitórias são importantes no futebol, mas não se pode reduzir o interesse pelo espetáculo a um pragmatismo utilitarista.

Se existe algo que comove os torcedores para além do dom-talento, é a demonstração de entrega irrestrita por parte dos atletas, ou seja, o dom que significa dádiva. Há momentos em que ganhando ou perdendo fica evidente que os atletas abdicaram de si mesmos para doar-se à equipe e, por extensão, à comunidade afetiva que deposita nele sua confiança. São momentos de entrega total, e por isso mesmo considerados sagrados, inesquecíveis para atletas e torcedores. Ponto no qual a dinâmica esportiva é vivenciada na mesma freqüência dos ritos mágicos e religiosos mais efusivos, nos quais os interesses utilitários se tornam uma quimera. O que os espetáculos futebolísticos - alguns, não todos - promovem não é um retorno ao passado, antes mostram que os afetos, os mistérios, o coletivo, o sagrado, o lúdico, o imaginário e tantas outras dimensões do pensamento simbólico continuam existindo concretamente.

\section{Notas}

1 As incessantes redefinições do conceito de $h a$ bitus (cf. Bourdieu, 1990; Bourdieu e Wacquant, 1995) corrigiram alguns mal-entendidos. Tais reelaborações dinamizaram a noção, aumentando suas possibilidades de uso que, em contraparti$\mathrm{da}$, se tornaram por vezes excessivas. Entre a lista interminável de críticas ao habitus, aquela per- 
tinente de ser invocada aqui é a de Bronckart e Schurmans (1999), dando conta de que a noção não pode ser usada, como freqüentemente ocorre, como teoria cognitiva.

2 Para uma argüição detalhada e prolongada neste sentido, conferir Damo (2007, pp. 185-195).

3 O leque de aptidões é extenso e variado na medida em que o futebol é um esporte de equipe e sua evolução instaurou a divisão social do trabalho, bem como a especialização de algumas funções para as quais são requeridas habilidades especiais.

4 A crença de que todos os futebolistas ganham muito e gastam mal é fantasiosa. Já foi suficientemente esclarecido que as cifras astronômicas são privilégios da minoria no futebol (Vieira, 2001). Em outra ocasião também argüi que o mercado profissional de "pés-de-obra" é menos rentável e mais precarizado do que se supõe quando acompanhamos o noticiário esportivo, que enfatiza apenas os grandes clubes ( $1^{\mathrm{a}}$ e $2^{\mathrm{a}}$ divisão nacionais), onde estão empregados menos de 20\% dos futebolistas (Damo, 2005, pp. 155-202).

Claro que os boleiros também praticam um consumo do tipo conspícuo, voltado à ostentação, investem seus dividendos ou poupam para garantir a aposentadoria precoce. Arriscaria dizer que a maioria dos jogadores bem-pagos faz as três coisas ao mesmo tempo, mas nenhum desses padrões de uso do dinheiro demarca a especificidade do campo futebolístico (Veblen, 1980; Lima, 2003).

Esta interpretação é inspirada num conjunto extenso de trabalhos que retomaram a discussão sobre "a força" do dom. Não havendo como recompor este debate, gostaria ao menos de indicar, além dos já citados - Caillé, Tarot e Karsenti -, a contribuição de Kilani (1995) e Babadzan (1998).

Para uma argüição mais detalhada a esse respeito, ver Damo (2005, pp. 57-96; 2007, pp. 49-67).
$9 \quad$ Na esteira de Mauss, Radcliffe-Brown (1973, p. 116) deu ao parentesco por brincadeira uma roupagem funcionalista, o que não retira sua atualidade. Na versão do antropólogo britânico, o parentesco por brincadeira seria uma espécie de simulacro, necessário para dar vazão a certas tensões decorrentes de relações assimétricas ou conflituosas (com relação aos aliados, por exemplo) estabelecidas pelo parentesco convencional.

10 Oito meses antes de deixar o Grêmio, havia boatos de que o jogador fora vendido ao Paris-SaitGermain por 80 milhões de euros, o que jamais se confirmou. De fato, o Grêmio só foi indenizado pelo clube francês depois de entrar com uma ação de representação na Fifa, tendo recebido algo em torno de 5 milhões de euros. A quantia é bem inferior aos 30 milhões faturados pelo Paris-SaitGermain com a venda do jogador ao Barcelona, dois anos depois de adquiri-lo. A esse respeito, ver o periódico eletrônico Sport no site http// www.sport.fr (consultado em 20 out. 2004).

\section{BIBLIOGRAFIA}

BABADZAN, Alain. (1998), "Pour en finir avec le hau: Mauss, les Maoris et la 'force des choses". La Revue du M.A.U.S.S., 12: 246-260, $2^{\circ}$ sem.

BAKTHIN, Mikhail. (1993), A cultura popular na Idade Média e no Renascimento. 2 ed. São Paulo/Brasília, Hucitec/Editora da UnB.

BOURDIEU, Pierre. (1990), Coisas ditas. São Paulo, Brasiliense.

BOURDIEU, Pierre \& WACQUANT, Loïc. (1995), Respuestas: por una antropología reflexiva. Cidade do México, Grijalbo.

BROMBERGER, Christian. (1995), Le match de football: ethnologie d'une passion partisane à Marseille, Naples et Turim. Paris, Éditions de la Maison des Sciences de l'Homme. nho e amigos de infância e/ou adolescência -, e ocorre nos dez primeiros anos de vida. Quase a metade dos entrevistados disse ter-se definido por um clube antes dos cinco anos de idade, o que prova o quanto as crianças são influenciadas desde muito cedo; apenas 10\% dos entrevistados declararam ter mudado de clube, sendo que mais

de $85 \%$ afirmaram que não mudariam "jamais".

gre (Damo, 1998, pp. 75-85) revelam que, em praticamente $70 \%$ dos casos, a escolha do clube ito do coração é feita por influência da rede de sociabilidade familiar - sobretudo avô, pai, irmão, tio ou primo - ou muito próxima a ela - padri- 
CAILlÉ, Alain. (1994), Don, intérêt et désintéressement: Bourdieu, Mauss, Platon e quelques autres. Paris, La Découverte/ M.A.U.S.S.

(1999), "Préface", in Camille Tarot, De Durkheim à Mauss: l'invention du symbolique, Paris, La Découverte/M.A.U.S.S. (2000), Antropologia do dom: o terceiro paradigma. Rio de Janeiro, Vozes.

. (2006), "O dom entre o interesse e 'desinteressamento", in Paulo Henrique Martins e Roberta Campos Bivar, Poliforina do dom, Recife, Editora Universitária da UFPE.

DAMO, Arlei. (1998), Para o que der e vier: o pertencimento clubístico no futebol brasileiro a partir do Grêmio Foot-Ball Porto Alegrense. Dissertação de mestrado, Porto Alegre, PPGAS/UFRGS.

(2005), Do dom à profissão: uma etnografia do futebol de espetáculo a partir da formação de jogadores no Brasil e na França. Tese de doutorado, Porto Alegre, UFRGS/PPGAS (Disponível no site http://www.biblioteca.ufrgs.br/Bibliotecadigital)

(2007), Do dom à profissão: a formação de futebolistas no Brasil e na França. São Paulo, Hucitec.

ELIAS, Norbert \& DUNNING, Eric. (1992), A busca da excitação. Lisboa, Difel.

FOURNIER, Marcel. (1994), Marcel Mauss. Paris, Fayard.

GEERTZ, Clifford. (1989), A interpretação das culturas. Rio de Janeiro, Guanabara.

GODELIER, Maurice. (2201), O enigma do dom. Rio de Janeiro, Civilização Brasileira.

HUIZINGA, Johan. (1971), Homo Ludens. São Paulo, Perspectiva.

KARSENTI, Bruno. (1997), L'bomme total: sociologie, anthropologie et philosophie chez Marcel Mauss. Paris, PUF.

KILANI, Mondher. (1995), "Que de Hau! Le débat autour de l'Essai sur le don et la cons- truction de l'objet en anthropologie", in J-M. Adam et al., Le discours anthropologique, Paris, Editions Payot Lausanne.

LÉVI-STRAUSS, Claude. (2003), "Introdução à obra de Maucel Mauss", in M. Mauss, Sociologia e antropologia II. São Paulo, Cosac\&Naify.

LIMA, Diana. (2003), "Antropologia do consumo: a trajetória de um campo em expansão". BIB - Revista de Informação Bibliográfica em Ciências Sociais, 56: pp. 93-108.

MAUSS, Marcel. (1969 [1926]). "Parentes à plaisanteries", in Oeuvres, Paris, Éditions de Minuit, vol. 2.

(1974a), "As técnicas corporais", in , Sociologia e antropologia II, São Paulo, EPU/Edusp.

(1974b), Ensaio sobre a dádiva, in Sociologia e antropologia II, São Paulo, EPU/Edusp.

(1979), "A expressão obrigatória de sentimentos", in Roberto Cardoso de Oliveira (org.), Marcel Mauss, São Paulo, Ática (col. Grandes Cientistas Sociais).

RADCLIFFE-BROWN, Alfred. (1973), "Os parentescos por brincadeira", in ., Estrutura e função na sociedade primitiva, Petrópolis,Vozes.

SCHNEIDER, David M. (1992), "Conclusion", in ., A critique of the study of kinship, Ann Arbor, The University of Michigan Press.

SIMMEL, Georg. (1998), "O dinheiro na cultura moderna", in Jessé Souza e Berthold Oëlze (orgs.), Simmel e a modernidade, Brasília, Editora da UnB.

SOLINAS, Pier Giordio. (1994), "Lêtre humain: une valeur qui n'a pas prix?". Terrain, 23: 123-136, out.

SUAUD, Charles. (1978), La vocation: conversion et reconversion des prêtres ruraux. Paris, Éditions de Minuit.

TAROT, Camille. (1999), De Durkheim à Mauss, l'invention du symbolique. Paris, La Découvert/M.A.U.S.S. 
VEBLEN, Thornstein. (1980), "Consumo conspícuo", in _.. Teoria da classe ociosa, São Paulo, Abril.

VEYNE, Paul. (1984), Acreditavam os gregos em seus mitos? São Paulo, Brasiliense. . (1987), "Olympie dans l'Antiquité". Esprit (La nouvel âge du sport), 4: 53-62.

(1976), Le pain et le cirque. Paris, Éditions du Seuil.

VIEIRA, Jose Jairo. (2001), Paixão nacional e mito social: a participação do negro no futebol, profissionalização e ascensão social. Tese de doutorado, Rio de Janeiro, Iuperj.

WACQUANT, Loïc. (2002), Corpo e alma: notas etnográficas de um aprendiz de boxe. Rio de Janeiro, Relume-Damará.

ZELIZER, Viviana. (1992), "Repenser le marché: la construction sociale du "marché aux bébés' aux États-Unis, 1870-1930”. Actes de la Recherche en Sciences Sociales, 94, set. 
DOM, AMOR E DINHEIRO NO FUTEBOL DE ESPETÁCULO

\section{Arlei Sander Damo}

Palavras-chave: Dom; Dinheiro; Amor; Futebol; Pertencimento.

Este texto tem como objeto analisar as tensões em torno do amor e do dinheiro no contexto do futebol de espetáculo. Inicialmente são explicitados os diferentes significados do dom, como sinônimo de talento e de dádiva, no contexto da formação de jogadores. Também serão problematizadas as tensões decorrentes do fato de que os torcedores, engajados ao espetáculo a partir do pertencimento clubístico, empenham amor e dinheiro nesse sistema, enquanto os atletas, em contrapartida, dispõem seus talentos. Um caso paradigmático de tensão nesse tipo de relação é descrito e analisado na última parte do artigo.

\section{GIFT, LOVE, AND MONEY IN THE} SPECTACLE SOCCER

\section{Arlei Sander Damo}

Keywords: Gift; Money; Love; Soccer; Belonging.

This paper aims at analyzing the tensions around love and money in the context of the spectacle soccer. Initially, the different meanings of the gift are expressed as synonyms of talent and endowment in the context of the formation of the players. I shall also question the tensions coming from the fact that supporters, engaged in the spectacle from the belonging to a club, committing love and money in the system, while the athletes, in return feature their talents. A paradigmatic tension case on such relation is described and analyzed in the last part of the article.
DON, AMOUR ET ARGENT DANS LE FOOTBALL DE SPECTACLE

\section{Arlei Sander Damo}

Mots-clés: Don; Argent; Amour; Football; Appartenance.

Ce texte a pour but d'analyser les tensions autour de l'amour et de l'argent dans le cadre du football de spectacle. Initialement sont expliqués les différents sens du don, synonyme de talent et de grâce, dans le contexte de la formation des footballeurs. Nous analysons aussi les tensions issues du fait que les supporters, engagés dans le spectacle à partir de l'appartenance à un club, engagent de l'amour et de l'argent dans ce système, tandis que les athlètes, en contrepartie, disposent de leur talent. Un cas paradigmatique de tension dans ce genre de relation est décrit et analysé dans la dernière partie de l'article. 